\title{
Cover crop
}

\author{
January is traditionally a time for reflections and resolutions. By looking back on the past year at \\ Nature Plants, we can perhaps see what might be in store for the year to come.
}

With this first issue of 2017, Nature Plants enters its third year of publication. It seems amazing to us that the journal is already two years old, and yet we hope that Nature Plants has, in that time, established itself as a journal worth paying attention to. If we have achieved this, it is because of the papers that we have published.

Over the past year we have published research Articles and Letters, Reviews, News and Views, Comments and Features, as well as Editorials and Research Highlights. This collection has proved popular with readers, such that over the year, the articles that we have published have been looked at more than 1.3 million times. The content also gained attention beyond our pages, with more than 60 items garnering Altmetric scores over 50.

However, bare statistics give a limited view. Instead, a glance at our covers (pictured) gives a reminder of the range of topics in Nature Plant's remit.

The January, April, August and September covers all related to detailed molecular or cellular biology studies looking at plant development, responses to light and drought, and reproduction. June and October featured genetic studies, although each with a very different focus. June's cover celebrated the genome sequencing of the wild relatives of the classic model plant Petunia, while in October, it was the ancestors of the Maroons of Suriname, illuminated by the rice that they carried with them from Africa.

As well as papers looking at the molecular scale, Nature Plants has an interest in wholeorganism studies. For example, our July cover featured the desert moss Syntrichia caninervis, which collects what little water there is in the air - and from dew fog and occasionally rain - using small hairs at the end of its leaves. Two months earlier, our cover showed ants feeding on nectar that was being released from wounds in the leaves of bittersweet nightshade, Solanum dulcamara. The plant produces sugary nectar in this unusual way as a defence mechanism, attracting ants that will attack and protect the plants from herbivores such as beetles and slugs that caused the damage in the first place.
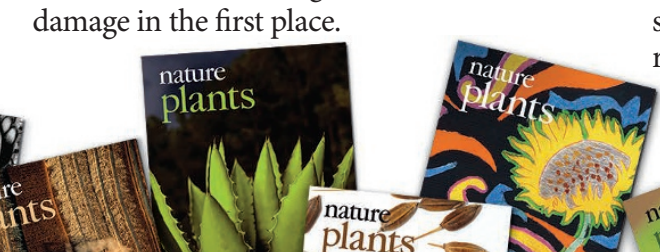

However, covers are not selected for the scientific importance of the work that they represent. We hope that all the studies we have published are significant, and interesting, and will continue to be so long after their publication date. It ants is far too early to guess which will be our standout papers in this regard. The genomes of rubber, Cardamine hirsuta and the parents of hybrid Petunia, all published in 2016, should provide resources upon which to build future work, but we would not necessarily consider them our highlights of the year. Looking back over what was published in 2016 in Nature Plants, the breadth of subjects covered may be more striking than any individual
The productivity and sustainability of organic farming practices came under the spotlight in February, while iridescent leaves were reflected in our cover in November. These two studies proved to be some of our most popular stories of the year in the wider media. The paper on the photonic properties of Begonia leaves, and how these might increase the efficiency of their photosynthesis in the lower-light environment of the forest understorey that is their natural habitat, was covered by over 30 news organizations worldwide. Meanwhile, the Review of organic farming was covered almost as much and produced a twitter flurry of 300 or so tweets.

However, the prize for the highest press coverage, if one existed, would face a tie between two papers, both of which were reported almost 80 times. The most recently published of these is a Brief Communication from November, showing that a species of ant from Fiji actively farms specific species of plant in a mutualistic relationship that has existed for around 3 million years. The other is the study that appeared on our March cover, reporting fossil flowers of an ancient Asterid that had been preserved in amber for at least 15 million years, and possibly for far longer.

Perhaps our most striking cover of all came in December, provoked by a study into the metabolism of Agave plants at a systems level; covering their gene expression, protein abundance and modification, and metabolite levels in different plant organs and over time. paper. There are papers exploring the atomic
details of photosynthesis, the genetic control of development, the signalling processes triggered by biotic and abiotic stresses, but there are also studies on the ecology of invasive species, and the monitoring of plant communities from space.

Looking forward, 2017 has been designated the International Year of Sustainable Tourism for Development by the United Nations. There can be little doubt that sustainability is a major focus of plant science; indeed, it is to be hoped that a practical outcome of plant science research is a sustainable global food supply. But the concept of sustainable tourism is a reminder that there is also a social dimension that cannot be ignored.

Nature Plants has always had an interest in the human aspects of plant research. In 2016, we published pieces on the commercialization and acceptance of transgenic crops in China, the social history of rubber cultivation, and the archaeobotany of grain processing. Now, in this first issue of 2017, a paper provides evidence for the preparation of vegetable material in pottery by people living in the then green Sahara more than 8,000 years ago.

In the coming year we hope to continue to publish the best and broadest selection of work in plant research. But while all the work will involve plants, it will not be only about the plants. We will also endeavour to explore the past, present and future interactions of plants and humankind. 
